\title{
RELAÇÃO ENTRE OOFORECTOMIA E PESO EM MODELO EXPERIMENTAL
}

\author{
RELATIONSHIP BETWEEN OVARIECTOMY AND BODY WEIGHT IN AN \\ EXPERIMENTAL MODEL
}

\author{
Leonardo de Souza Vasconcellos ${ }^{1}$; Kelly Renata Sabino²; Andy Petroianu, TCBC-MG ${ }^{3}$
}

\begin{abstract}
RESUMO: Objetivo: Avaliar a influência da privação dos hormônios ovarianos no ganho ponderal, em modelo experimental. Método: Foram utilizadas 40 ratas fêmeas adultas, distribuídas aleatoriamente em três grupos: Grupo 1 ( $\mathrm{n}=10$ ) - controle, Grupo 2 $(n=10)$ - submetido apenas à laparotomia, Grupo $3(n=20)$ - submetido à ooforectomia total bilateral. Os animais foram pesados semanalmente durante 30 semanas e os resultados foram avaliados pelo teste t de Student, com significância para $p<0,05$. Resultados: As ratas ooforectomizadas apresentaram ganho ponderal maior do que as demais, sendo a diferença significativa a partir da $9^{a}$ semana e persistindo até o fim do experimento. Conclusão: No presente trabalho, a privação dos hormônios ovarianos foi um fator relacionado com o maior ganho ponderal, em ratas (Rev. Col. Bras. Cir. 2005; 32(3): 132-135).
\end{abstract}

Descritores: Ovariectomia; Peso corporal; Estradiol; Progesterona; Modelos animais.

\section{INTRODUÇÃO}

Vários trabalhos enfatizaram perda da função ovariana devido a procedimentos cirúrgicos, radioterápicos e quimioterápicos, além de quadros infecciosos pélvicos graves com lesão dos ovários ${ }^{1}$. Essa privação dos hormônios ovarianos acarreta diversos distúrbios endócrinos e funcionais, tais como disfunção sexual, perda da libido, maior risco de osteoporose e de doenças cardíacas ${ }^{2}$. A interação entre os esteróides ovarianos e o ganho ponderal também vem sendo avaliada rotineiramente ${ }^{3,4}$.

Sabe-se que no período do climatério, as mulheres tendem ao aumento da gordura corporal e queda do metabolismo basal, quando comparadas com os homens ${ }^{1}$. Questiona-se também a influência de diversos fatores freqüentes no climatério, tais como os quadros psíquicos, as alterações de humor e estados depressivos, hábitos alimentares inadequados, além do sedentarismo . $^{5}$.

A obesidade é genericamente definida como uma doença universal e progressiva, caracterizada por excesso de gordura corporal, nociva à saúde 6 . Muitos fatores estão envolvidos na sua patogênese, incluindo controle do comportamento alimentar, mecanismos de armazenamento de gordura, regulação do aporte de energia e do gasto energético, bem como influências genéticas e psicológicas. O ganho excessivo de peso também foi identificado como fator de risco para diabetes do tipo 2, hipertensão arterial e doenças cardiovasculares ${ }^{7}$.

A relação entre hormônios femininos e variação ponderal em modelo experimental também vem sendo pesquisada. Vários autores descreveram ganho ponderal em animais ooforectomizados ${ }^{3,4,8}$. Com o advento da terapia de reposição hormonal e a descoberta da leptina, um hormônio regulador da obesidade, a discussão sobre obesidade e supressão estrogênica vem sendo mais freqüente ${ }^{9}$.

Diante da possível relação entre ooforectomia e ganho ponderal, o presente estudo foi realizado com o objetivo de avaliar a influência da privação dos hormônios femininos na variação ponderal em modelo experimental.

\section{MÉTODO}

Este trabalho foi realizado de acordo com as recomendações das Normas Internacionais de Proteção aos Animais e do Código Brasileiro de Experimentação Animal (1988), e aprovado pela Comissão de Ética do Departamento de Cirurgia da Faculdade de Medicina da Universidade Federal de Minas Gerais.

Foram utilizados 40 ratos fêmeas da raça Wistar, adultos (100 dias de vida), pesando aproximadamente $200 \pm 15$ gramas, obtidas no Biotério Central do Instituto de Ciências Biológicas - ICB/UFMG.

Os animais foram distribuídos aleatoriamente em três grupos: Grupo $1(\mathrm{n}=10)$ : controle, não operado; Grupo $2(\mathrm{n}=10)$ : laparotomia e identificação dos ovários; Grupo $3(n=20)$ : ooforectomia bilateral.

As intervenções foram realizadas sob anestesia com cloridrato de quetamina $(90 \mathrm{mg} / \mathrm{kg})$ e cloridrato de xilazina $(10 \mathrm{mg} /$ $\mathrm{kg}$ ), ambos intramuscular. Nos Grupos 2 e 3, realizou-se laparotomia mediana de quatro centímetros de extensão. No Grupo 2 os ovários foram preservados, e no Grupo 3, foram retirados. $\mathrm{O}$ fechamento da parede abdominal foi em dois planos, com pontos simples, utilizando fio de polipropileno monofilamentar 5-0 para a aponeurose e mononáilon 4-0 para a pele.

1. Residente de Patologia Clínica do Hospital das Clínicas da UFMG.

2. Residente de Cirurgia Geral do Hospital Luxemburgo de Belo Horizonte.

3. Professor Titular do Departamento de Cirurgia da Faculdade de Medicina - UFMG; Docente Livre da Faculdade de Medicina de Ribeirão Preto - USP; Docente Livre da Escola Paulista de Medicina - UNIFESP; Doutor em Fisiologia e Farmacologia - ICB / UFMG, Pesquisador IA do CNPq. Recebido em 29/12/2004

Aceito para publicação em 17/03/2005

Trabalho realizado no Departamento de Cirurgia, Faculdade de Medicina. Universidade Federal de Minas Gerais. Auxílio Financeiro: FAPEMIG e CNPq. 
Tabela 1 - Pesos corpóreos (média \pm desvio padrão) dos animais em cada grupo, no pré e pós-operatório (PO), durante 30 semanas.

\begin{tabular}{cccc}
\hline Semanas & \multicolumn{3}{c}{ Variação ponderal dos grupos (g) } \\
\cline { 2 - 4 } & 1 - Controle & 2 - Laparotomia & 3 - Ooforectomia \\
\hline Peso inicial & $210,65 \pm 12,2$ & $206,22 \pm 14,14$ & $205,45 \pm 15,35$ \\
$1^{\text {a }}$ & $208,14 \pm 15,39$ & $204,68 \pm 18,60$ & $203,25 \pm 16,18$ \\
$5^{\text {a }}$ & $232,86 \pm 12,68$ & $224,65 \pm 20,44$ & $243,14 \pm 18,16$ \\
$9^{a}$ & $254,92 \pm 14,03$ & $241,16 \pm 18,88$ & $278,02 \pm 19,40 *$ \\
$13^{a}$ & $266,60 \pm 14,41$ & $261,52 \pm 16,40$ & $293,70 \pm 20,18 *$ \\
$17^{a}$ & $277,70 \pm 13,94$ & $272,16 \pm 22,58$ & $308,71 \pm 21,99 * *$ \\
$21^{a}$ & $291,46 \pm 17,59$ & $281,03 \pm 26,16$ & $324,23 \pm 24,35 * *$ \\
$25^{a}$ & $295,60 \pm 16,41$ & $289,30 \pm 27,32$ & $329,50 \pm 25,15 * *$ \\
$30^{a}$ & $299,30 \pm 17,29$ & $293,20 \pm 27,86$ & $332,40 \pm 25,71 * *$ \\
\hline
\end{tabular}

Teste $t$ de Student $-p<0,05$ (*) entre os grupos 2 e 3.

Teste $t$ de Student $-p<0,05$ (**) entre os grupos 1 e 3; 2 e 3.

No pós-operatório, para todos os animais foi ofertada mesma quantidade de água e ração. Avaliou-se ainda a média de ração ingerida por cada rata, anotando os pesos das rações no início e fim de 24 horas, nos dias das pesagens. Para que houvesse uniformidade na quantidade de animais por dieta oferecida, as ratas de todos os grupos foram separadas em gaiolas com cinco animais cada.

A variação ponderal de cada grupo foi estudada comparativamente durante um período de 30 semanas. Os animais foram pesados semanalmente, pelo mesmo observador, em uma balança de precisão com capacidade para 500 gramas.

Ao final do período de estudo, os animais foram disponibilizados para outros experimentos, dentro da mesma linha de pesquisa.

A análise estatística foi conduzida com base no teste t de Student, considerando valores significativos os correspondentes a $\mathrm{p}<0,05$.

\section{RESULTADOS}

Todos os animais sobreviveram ao procedimento operatório e evoluíram sem intercorrências durante todo o período do estudo.

A Tabela 1 mostra a média ponderal das ratas em cada grupo, no pré e pós-operatório, no período estudado. Nota-se que os pesos iniciais dos três grupos foram semelhantes entre si ( $p>0,05)$. Em todos os animais operados houve uma redução ponderal na primeira semana. A partir da segunda semana, houve um aumento progressivo e proporcional do peso das ratas. As diferenças de peso entre os três grupos tornaram-se significativas a partir da nona semana e assim se mantiveram até o final do experimento. Observa-se que o Grupo 3 (ooforectomizado) apresentou maior ganho de peso em relação aos outros grupos.

O consumo individual de ração foi semelhante nos três grupos avaliados, em média de $15 \pm 5$ gramas/animal, não havendo diferença entre o peso total das rações entre as gaiolas nos diferentes períodos deste trabalho.

A Figura 1 ilustra o peso de cada grupo, em intervalos de quatro semanas de pós-operatório.

\section{DISCUSSÃO}

Muitos são os trabalhos na literatura que estudam os efeitos dos esteróides sexuais sobre o metabolismo corpóreo $^{1-9}$. Dentre os modelos experimentais, os ratos albinos são os mais utilizados por apresentarem um ciclo estral bastante conhecido e de curta duração (média de 4-5 dias) e atingirem rapidamente o amadurecimento sexual aos 50-60 dias de vida. Seu breve período gestacional, médio de 21 a 23 dias, e sua considerável prole, de oito a 14 filhotes (média 10 a 12), são características marcantes desses animais. Outros fatores importantes são a alta possibilidade de procriação anual, até sete vezes por ano, com período fértil variando entre um e dois anos, acompanhando sua expectativa de vida, de 2,5 a três anos de idade ${ }^{10}$.

A variedade de fatores que interagem no ganho ponderal, tais como hereditariedade, hábito alimentar, exercícios físicos, sedentarismo, distúrbios psiquiátricos, entre outros,${ }^{7}$ bem como as diversidades metodológicas adotadas nos trabalhos, contribui para resultados conflitantes sobre a relação entre supressão hormonal e ganho ponderal ${ }^{3,4,5,8}$. No pre-

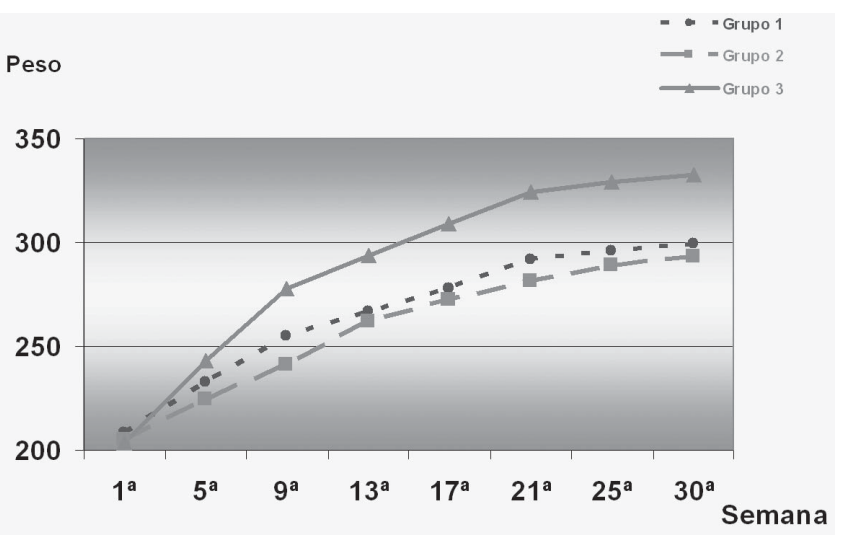

Figura 1 - Gráfico que mostra evolução ponderal dos animais em cada grupo, durante 30 semanas de pós-operatório.

Legenda: Grupo 1 - controle

Grupo 2 - laparotomia com preservação dos ovários

Grupo 3 - ooforectomia

Teste $t$ de Student - $p<0,05$ (*) entre os grupos 2 e 3

Teste $t$ de Student - $p<0,05$ (**) entre os grupos 1 e 3; 2 e 3 
sente estudo, procurou-se eliminar tais interferências, utilizando animais de mesma linhagem, idade e peso iniciais, tipo e quantidade nutricional uniforme, e mesmo número de animais por gaiola. Dessa forma, a única variável foi a ooforectomia.

Por não ter sido utilizado gaiola metabólica para estudar uma possível variação ponderal pela variação do consumo calórico e quantificação das perdas dos dejetos dos animais, não foi possível detectar adequadamente a quantidade de alimento consumido pelas ratas. Entretanto, como o ganho ponderal dos animais foi de poucas gramas por dia, com variação diária não significativa entre eles, o presente estudo foi conduzido em intervalos semanais. Para maior destaque dessa variação ponderal entre os grupos, apresentou-se uma periodicidade de quatro em quatro semanas, conforme demonstrado na Figura 1.

Devido à resposta orgânica ao trauma, todos os animais submetidos ao ato operatório reduziram o peso corporal na primeira semana. Os animais não operados e os submetidos apenas à laparotomia tiveram pesos semelhantes ao final do experimento. As ratas ooforectomizadas apresentaram ganho ponderal significativo a partir da $9^{\mathrm{a}}$ semana, mantendo-se assim até a $30^{\text {a }}$ semana, quando se observou uma tendência para estabilização dos pesos dos animais, interrompendo-se as medições.

O ganho ponderal pós-ooforectomia pode estar relacionado com a supressão dos hormônios ovarianos, tendo em vista que o estrogênio aumenta o consumo energético e, como conseqüência, diminui o peso corporal ${ }^{9,11}$. Portanto, se houver supressão estrogênica, o consumo de energia será menor e os animais terão aumento ponderal. Outros trabalhos também verificaram ganho de peso maior em animais ooforectomizados ${ }^{3,8}$. Por outro lado, segundo estudo de Geary et $\mathrm{al}^{4}$ ratas ooforectomizadas tratadas com estradiol engor- dam menos, enquanto que animais que recebem progesterona são mais magros $^{11}$.

O estrogênio é capaz de manter a distribuição de gordura corporal no período pós-puberal e sua deficiência eleva o depósito adiposo visceral com aumento da relação cinturaquadril, características andróides ${ }^{13}$. Seu papel na redução do nível sérico de leptina e inibição da ingestão de alimentos reduz o peso corpóreo. A influência dos hormônios androgênicos da supra-renal e a interação entre estrogênio e leptina, também contribuem para o ganho ponderal ${ }^{9}$.

Além de estudos experimentais, ensaios clínicos também mostraram associação entre esteróides sexuais, leptina e variação ponderal. A terapia de reposição hormonal em mulheres ooforectomizadas aumenta a concentração de leptina plasmática e reduz a obesidade ${ }^{9,13,14}$. O Instituto Brasileiro de Geografia e Estatística (IBGE) verificou aumento na proporção de brasileiros obesos, principalmente entre as mulheres, na faixa dos 45 a 64 anos $^{15}$. Essa idade também representa o período do climatério feminino, com decréscimo da função ovariana ${ }^{1,2,5}$. Observou-se ainda que mulheres em menopausa e sem reposição hormonal apresentam-se mais obesas em relação aquelas que fazem uso regular de hormônios ${ }^{16}$.

Concluindo, baseado nos resultados do presente trabalho, a privação dos hormônios ovarianos é relacionada com ganho ponderal, em ratos fêmeas.

\section{AGRADECIMENTOS}

Os autores agradecem ao Sr. Darcy Ferreira dos Santos pelos animais do presente trabalho. Somos gratos também ao CNPq e FAPEMIG pelos auxílios financeiros que permitiram a realização deste estudo.

\begin{abstract}
Background: Assess the effects of the ovarian hormones privation on the body weight, in experimental model. Methods: Forty adult female rats were randomly divided into three groups: Group $1(n=10)$ - control, Group $2(n=10)$-sham operation, Group $3(n=20)$ - ovariectomy. The weight of the animals was weekly assessed during 30 weeks and the results were compared by Student t test, with significance for $p<0.05$. Results: The ovariectomized rats presented higher weight gain than those of the other groups. The difference was significant after nine weeks, until the end of the experiment. Conclusion: In the present work, privation of the ovarian hormones was related to higher body weight, in rats.
\end{abstract}

Key-words: Ovariectomy; Body weight; Estradiol; Progesterone; Female Rat.

\section{REFERÊNCIAS}

1. Davis SR, Buerger HG - Clinical reviews 82: Androgens and postmenopausal woman. J Clin Endocrinol Metab. 1996;81(8):2759-63.

2. Speroff T, Dawson NV, Speroff L, et al. - A risk-benefit analysis of elective bilateral oophorectomy; effect of changes in complicance with estrogen therapy on outcome. Am J Obstet Gynecol. 1991;164(1 Pt 1):165-74.

3. Fisher JS, Kohrt WM, Brown M - Food restriction suppresses muscle growth and augments osteopenia in ovariectomized rats. J Appl Physiol. 2000;88(1):265-71.
4. Geary N, Asarian L - Cyclic estradiol treatment normalizes body weight and test meal size in ovariectomized rats. Physiol Behav. 1999;67(1):141-7.

5. Souza ELBL, Andrade AV - A importância da atividade física no climatério e aspectos do tratamento fisioterapêutico. In: Marinho R. Climatério. $2^{\text {a }}$ ed. Rio de Janeiro: Medsi; 2000. p. 371-7.

6. Health implications of obesity. National Institutes of Health Consensus Development Conference Statement. Ann Intern Med. 1985;103(6 Pt 2):1073-7.

7. Agras WS - Obesity. In: Dale DC, Federman DD, Cassel CK. Scientific American Medicine. New York: Scientific American Inc, 1996. p.1-9. 
8. Szabo J, Ibrahim WH, Sunvold GD, et al. - Effect of dietary protein quality and essential fatty acids on fatty acid composition in the liver and adipose tissue after rapid weight loss in overweight cats. Am J Vet Res. 200;64(3):310-5.

9. Shimomura K, Shimizu H, Tsuchiya T, et al. - Is leptin a key factor which develops obesity by ovariectomy? Endocr J. 2002;49(4):417-23.

10. Kohn DF, Barthold SW - Biology and diseases of rats. In: Fox JG, Cohen BJ, Loew FM. Laboratory Animal Medicine. London: Academic Press, 1984. p. 91-9.

11. Guyard B, Fricker J, Brigant L, et al. - Effects of ovarian steroids on energy balance in rats fed a highly palatable diet. Metabolism. 1991;40(5):529-33.

12. Bond EF, Heitkemper MM, Jarrett M - Intestinal transit and body weight responses to ovarian hormones and dietary fiber in rats. Nurs Res. 1994;43(1):18-24.

13. Ley CJ, Lees B, Stevenson JC - Sex-and menopause-associated changes in body-fat distribution. Am J Clin Nutr. 1992;55(5):950-4.
14. Tommaselli GA, Di Carlo C, Nasti A, et al. - Effects of bilateral ovariectomy and postoperative hormonal replacement therapy with 17 beta-estradiol or raloxifene on serum leptin levels. Menopause. 2003;10(2):160-4.

15. Sichieri R, Coitinho DC, Leao MM, et al. - High temporal, geographic, and income variation in body mass index among adults in Brazil. Am J Pub Health. 1994;84(2):793-8.

16. Eraker SA, Kirscht JP, Becker MH - Understanding and improving patient compliance. Ann Intern Med. 1984;100(2):258-68.

Endereço para correspondência:

Leonardo de Souza Vasconcellos

Avenida Cristóvão Colombo, $\mathrm{n}^{\circ}$ 506, Apto 51.

CEP 30140-150, Belo Horizonte, Minas Gerais.

E-mail: leonardos_vasconcellos@yahoo.com.br 